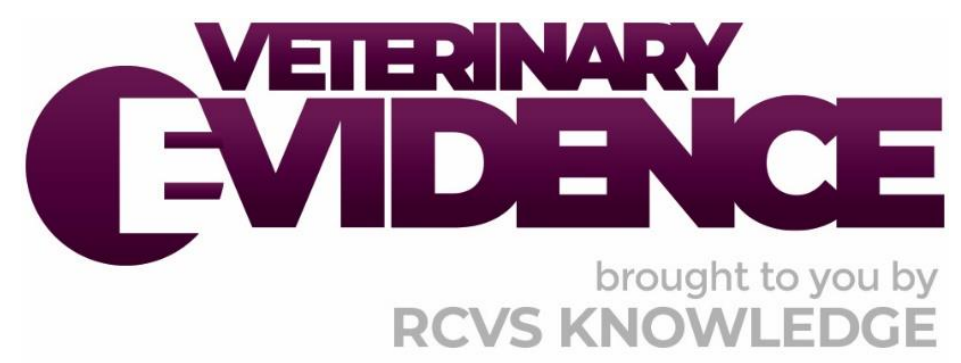

\title{
Can measurement of glucose levels in blood and peritoneal fluid be used to diagnose septic peritonitis in dogs?
}

\author{
A Knowledge Summary by
}

Nicole D'Mello BVMSci (Hons) MRCVS ${ }^{1 *}$

\footnotetext{
${ }^{1}$ University of Surrey School of Veterinary Medicine, VSM Building, University of Surrey, Daphne Jackson Rd, Guildford GU2 7AL

*Corresponding Author (nicoledmello@hotmail.com)
}

ISSN: 2396-9776

Published: 02 Mar 2022

in: Veterinary Evidence Vol 7, Issue 1

DOI: https://doi.org/10.18849/ve.v7i1.382

Reviewed by: Adam Swallow (BVSc MRCVS) and Theodora Tsouloufi (DVM PhD AFHEA MRCVS) 


\section{KNOWLEDGE SUMMARY}

\section{PICO question}

Can the measurement of blood and peritoneal fluid effusion glucose levels be used to accurately diagnose septic peritonitis in dogs when compared to cytology and bacterial culture?

\section{Clinical bottom line}

\section{Category of research question}

\section{Diagnosis}

\section{The number and type of study designs reviewed}

Three papers were critically reviewed, all of which were diagnostic test evaluation studies

\section{Strength of evidence}

Moderate

\section{Outcomes reported}

Glucose measurements can be used to diagnose septic peritonitis when the blood plasma glucose level is $>2.1 \mathrm{mmol} / \mathrm{L}$ higher than that of the peritoneal fluid glucose when using a veterinary point of care (POC) glucometer. If using a biochemistry analyser, a whole blood glucose $>1.1 \mathrm{mmol} / \mathrm{L}$ higher than that of the peritoneal fluid can be used to diagnose septic peritonitis. This is only relevant when the peritoneal fluid is collected by abdominocentesis and not in a postoperative period

\section{Conclusion}

At present, there is moderate evidence that glucose measurements are useful as a patient side test for the diagnosis of septic peritonitis and are especially useful in cases where intracellular bacteria cannot be identified on cytology. However, despite the so far promising accuracy results, the cut-offs reported are quite variable and overall, there is not a single diagnostic test that is $100 \%$ sensitive and specific in repeated studies. Therefore, the results of the glucose measurements should be evaluated alongside other biomarker testing, imaging modalities and the clinical presentation of the patient. Glucose measurements cannot currently replace culture / sensitivity and cytology as the gold standard for the diagnosis of septic peritonitis

\section{How to apply this evidence in practice}

The application of evidence into practice should take into account multiple factors, not limited to: individual clinical expertise, patient's circumstances and owners' values, country, location or clinic where you work, the individual case in front of you, the availability of therapies and resources.

Knowledge Summaries are a resource to help reinforce or inform decision making. They do not override the responsibility or judgement of the practitioner to do what is best for the animal in their care.

\section{Clinical scenario}

A veterinarian is working the out of hours shift when a client brings in their 5 year old Golden Retriever. The dog is a known scavenger and is now presenting with anorexia, lethargy and abdominal pain. A quick ultrasound scan shows a small amount of free fluid in the abdomen. The veterinarian suspects this is case of septic peritonitis but they could not find any intracellular bacteria in the peritoneal fluid sample they took and 
cannot wait for results from bacterial culture. The veterinarian wonders if they can measure the glucose levels in blood and peritoneal fluid instead to reliably confirm their working diagnosis.

\section{The evidence}

The search identified three diagnostic test evaluation studies that were related to the PICO question. The experimental designs provide a moderate strength of evidence as the studies were generally well planned, the patient follow-up was good and all studies were carried out in a realistic clinical setting. The main limitation in all the studies was the small sample size.

\section{Summary of the evidence}

\section{Bonczynski et al. (2003)}

\begin{tabular}{|c|c|}
\hline Population: & $\begin{array}{l}\text { Mixed population of dogs and cats with naturally occurring } \\
\text { peritoneal effusions, presenting at a referral practice. }\end{array}$ \\
\hline Sample size: & $\begin{array}{l}18 \text { dogs: } \\
\text { - Seven septic peritoneal effusions } \\
\text { - } 11 \text { nonseptic peritoneal effusions (control group) }\end{array}$ \\
\hline Intervention details: & $\begin{array}{l}\text { Minimum of } 1 \mathrm{ml} \text { of venous blood and } 1 \mathrm{ml} \text { of peritoneal effusion } \\
\text { collected from all patients and placed into heparinised tubes. The } \\
\text { samples were frozen immediately and analysed by the same person } \\
\text { each time within } 24 \text { hours. }\end{array}$ \\
\hline Study design: & Diagnostic test validation study. \\
\hline Outcome studied: & $\begin{array}{l}\text { All objective assessments (relevant to the PICO question): } \\
\text { - Glucose was measured on all blood and peritoneal fluid } \\
\text { samples using a blood chemistry analyser; VetTest } 8008 \\
\text { analyser (VetTest Analyzer; Idexx). } \\
\text { - Total nucleated cell count was measured on peritoneal fluid } \\
\text { in all patients. } \\
\text { - The blood to fluid glucose (BFG) were measured by } \\
\text { subtracting the peritoneal fluid concentration from the } \\
\text { blood concentration. } \\
\text { - All peritoneal fluid samples were submitted for cytology (for } \\
\text { presence of intracellular bacteria) and bacterial culture to } \\
\text { determine if patients had septic peritonitis (SP) or nonseptic } \\
\text { peritonitis (NSP). } \\
\text { - Sensitivity, specificity, positive predictive value (PPV) and } \\
\text { negative predictive value (NPV) were determined. } \\
\text { Other biomarkers were measured in this study however they were } \\
\text { not directly relevant to the PICO question and therefore will not be } \\
\text { commented on further in this Knowledge Summary. }\end{array}$ \\
\hline $\begin{array}{l}\text { Main findings: } \\
\text { (relevant to PICO question): }\end{array}$ & $\begin{array}{l}\text { Peritoneal fluid glucose concentration was significantly } \\
\text { lower ( } P=0.008) \text { in dogs with septic effusion than those } \\
\text { with nonseptic effusion. } \\
\text { - The median BFG difference was significantly higher in dogs } \\
\text { with septic effusion than those with nonseptic effusion ( } P= \\
0.0005) \text {. } \\
\text { - A BFG difference }>20 \mathrm{mg} / \mathrm{dL}(>1.1 \mathrm{mmol} / \mathrm{L}) \text { was } 100 \% \\
\text { sensitive and specific for diagnosis of SP in dogs, with PPV } \\
\text { and NPV of } 100 \% \text {. }\end{array}$ \\
\hline
\end{tabular}




\begin{tabular}{|l|l|}
\hline & In septic dogs, peritoneal fluid glucose measurements $<50$ \\
& $\mathrm{mg} / \mathrm{dL}(<2.8 \mathrm{mmol} / \mathrm{L})$ were $57 \%$ sensitive and $100 \%$ specific, \\
& with a PPV and NPV of $83 \%$. \\
\hline Limitations: & BFG difference is more reliable for diagnosis of SP than \\
& peritoneal fluid glucose measurements alone. \\
\hline - & Small sample size of 18 dogs reduces the reliability of the \\
& results. \\
- & There is an absence of descriptive statistics (breed, age, \\
& gender, etc.) for the study population. This is relevant as a \\
& more varied population has a greater applicability to general \\
clinical practice. & \\
The glucose concentration was determined using a blood \\
chemistry analyser which is not always practical for \\
emergency patient side testing. \\
The control population of dogs were not matched based on \\
clinical history, exam findings or severity of illness and were \\
not that clinically similar to dogs with SP. Not all the controls \\
had an inflammatory effusion, some were neoplastic. \\
Animals were sampled only once (at presentation). This does \\
not allow for mapping of the changes in biomarker \\
concentration over time. Time since onset of disease may \\
affect biomarker concentrations and therefore may reduce \\
the reliability and significance of the results. \\
This study was conducted in a referral practice. Patients \\
presenting are typically at a severe stage in the disease \\
process. Results from this study may not be directly \\
applicable to patients with the same disease at an earlier or \\
milder stage in the disease process, as is often seen in first \\
opinion general practice. \\
\hline
\end{tabular}

\section{Koenig \& Verlander (2015)}

\begin{tabular}{|c|c|}
\hline Population: & $\begin{array}{l}\text { Mixed population of dogs with naturally occurring peritoneal } \\
\text { effusions presenting at referral hospitals. }\end{array}$ \\
\hline Sample size: & 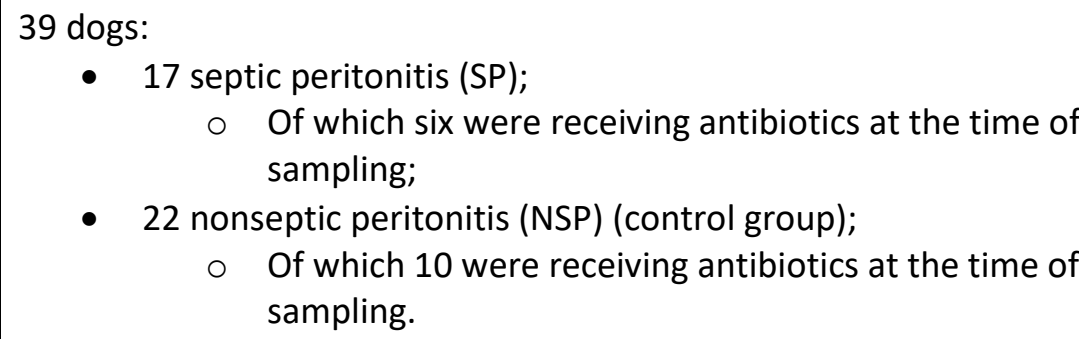 \\
\hline Intervention details: & $\begin{array}{l}\text { All samples were collected concurrently on first presentation of } \\
\text { peritoneal effusion: } \\
\text { - Collection of venous whole blood, kept in heparinised tube. } \\
\text { - Collection of peritoneal fluid via aseptic abdominocentesis. } \\
\text { - All samples were analysed with a veterinary point of care } \\
\text { (POC) glucometer immediately after collection. } \\
\text { - Samples were then centrifuged to obtain plasma and } \\
\text { peritoneal supernatant and then tested with a veterinary } \\
\text { POC glucometer. }\end{array}$ \\
\hline
\end{tabular}




\begin{tabular}{|c|c|}
\hline Study design: & Diagnostic test validation study. \\
\hline Outcome studied: & $\begin{array}{l}\text { Objective outcomes studied (relevant to PICO question): } \\
\text { - Glucose concentration in whole blood and peritoneal fluid } \\
\text { using a veterinary POC glucometer. } \\
\text { Glucose concentration in plasma and peritoneal fluid } \\
\text { - } \text { supernatant using a veterinary POC glucometer. } \\
\text { Peritoneal fluid cytology for bacterial identification and } \\
\text { bacterial culture for diagnosis of SP. } \\
\text { Sensitivity, specificity, positive predictive value (PPV) and } \\
\text { negative predictive value (NPV) of glucose concentration } \\
\text { differences for whole blood to peritoneal fluid (WB-PF), } \\
\text { plasma to peritoneal fluid (P-PF) and plasma to peritoneal } \\
\text { fluid supernatant (P-PFS) for the diagnosis of SP was } \\
\text { determined. } \\
\text { Other biomarkers were measured in this study however they were } \\
\text { not directly relevant to the PICO question and therefore will not be } \\
\text { commented on further in this Knowledge Summary. }\end{array}$ \\
\hline $\begin{array}{l}\text { Main findings: } \\
\text { (relevant to PICO question): }\end{array}$ & $\begin{array}{l}\text { There was a significant and clinically relevant difference in glucose } \\
\text { concentration when measured with a veterinary POC glucometer in } \\
\text { whole blood versus plasma }(P<0.001) \text { but not between peritoneal } \\
\text { fluid and peritoneal supernatant }(P=0.140) \text {. } \\
\text { When using a veterinary POC glucometer with a cut off of }>20 \mathrm{mg} / \mathrm{dL} \\
(>1.1 \mathrm{mmol} / \mathrm{L}) \text { : } \\
\text { - } \quad \text { WB-PF difference was not an acceptable method of } \\
\quad \text { diagnosing SP with a sensitivity of } 41.2 \% \text {, specificity of } 100 \% \text {, } \\
\text { PPV of } 100 \% \text { and NPV of } 68.8 \% \text {. } \\
\text { - P-PF difference improved the diagnostic accuracy with } \\
\quad \text { sensitivity of } 88.2 \% \text {, specificity of } 80 \% \text {, PPV of } 78.9 \% \text { and } \\
\text { NPV of } 88.9 \% \text {. } \\
\text { When using a veterinary POC glucometer with a cut-off of }>38 \\
\text { mg/dL ( }>2.1 \text { mmol/L): } \\
\text { - P-PF difference improved the diagnostic accuracy with } \\
\text { sensitivity of } 88.2 \% \text {, specificity of } 100 \% \text {, PPV of } 100 \% \text { and } \\
\text { NPV of } 90.9 \% \text {. } \\
\text { - P-PF difference had the best diagnostic accuracy at } 94.6 \% \text {. }\end{array}$ \\
\hline Limitations: & $\begin{array}{l}\text { - One dog included in the study was administered dextrose } \\
\text { before blood glucose was measured which can elevate blood } \\
\text { glucose measurements therefore causing a greater } \\
\text { difference between blood and peritoneal fluid glucose } \\
\text { concentrations. It may have been assumed that this } \\
\text { difference was due to the disease process rather than the } \\
\text { administration of dextrose. } \\
\text { - For a diagnosis of SP, patients had to have bacteria } \\
\text { identified on cytology or a positive culture result. However, } \\
\text { only } 3 / 22 \text { dogs with nonseptic peritoneal effusion had } \\
\text { peritoneal fluid sent for culture. This could have led to a } \\
\text { misdiagnosis of a sterile effusion based on a combination of } \\
\text { results from cytology and post mortem findings but without } \\
\text { the added negative culture result. This may have affected } \\
\text { the sensitivity and specificity of the study. }\end{array}$ \\
\hline
\end{tabular}




\begin{tabular}{|l|l|}
\hline If the glucose level in any sample was too low to give an \\
objective reading, the patient would be assigned a glucose \\
level of $20 \mathrm{mg} / \mathrm{dL}(1.1 \mathrm{mmol} / \mathrm{L})$. In one case this meant there \\
was a minimal difference in fluid glucose as the patients' \\
blood glucose was $28 \mathrm{mg} / \mathrm{dL}(1.55 \mathrm{mmol} / \mathrm{L}$ ) and so the cut- \\
off value of $>20 \mathrm{mg} / \mathrm{dL}$ could not be reached. Therefore, the \\
patient would have been misdiagnosed with a nonseptic \\
effusion. This reduces the sensitivity of the data in terms of \\
using a veterinary POC glucometer and may explain why \\
using a biochemistry analyser is more sensitive. \\
The small sample size reduces the reliability of the results. \\
The researcher conducting the fluid analysis was not blinded \\
to the patient presentation, clinical signs or any other test \\
results. Researcher bias will affect the validity of the result, \\
although in this case it may be less significant as the fluid \\
analysis is an objective measure. \\
This study was conducted in a referral practice. Patients \\
presenting are typically at a severe stage in the disease \\
process. Results from this study may not be directly \\
applicable to patients with the same disease at an earlier or \\
milder stage in the disease process, as is often seen in first \\
opinion general practice.
\end{tabular}

Martiny \& Goggs (2019)

\begin{tabular}{|c|c|}
\hline Population: & $\begin{array}{l}\text { Mixed population of dogs with naturally occurring systemic } \\
\text { inflammatory response syndrome and / or peritoneal effusion, } \\
\text { presenting at primary and referral practice. }\end{array}$ \\
\hline Sample size: & $\begin{array}{l}37 \text { dogs: } \\
\begin{aligned}-18 \text { with septic peritonitis (SP); } \\
\circ \quad \text { Diagnosed by either positive bacterial culture, } \\
\text { intracellular bacteria on cytology or gross evidence } \\
\text { of gastrointestinal perforation at surgery. }\end{aligned} \\
\text { - } 19 \text { with nonseptic ascites (NSA) (age-matched controls). }\end{array}$ \\
\hline Intervention details: & $\begin{array}{l}\text { - Peritoneal fluid sampled via abdominocentesis and placed } \\
\text { into heparinised, ethylenediaminetetraacetic acid (EDTA), } \\
2 \% \text { sodium citrate and plain tubes. } \\
\text { - Blood samples were collected via venipuncture or } \\
\text { intravenous catheterisation and placed into heparinised, } \\
\text { EDTA, 3.2\% sodium citrate and plain tubes. }\end{array}$ \\
\hline Study design: & Diagnostic test evaluation study. \\
\hline Outcome studied: & $\begin{array}{l}\text { Samples from SP (18) were paired with (19) age-matched controls } \\
\text { for statistical analysis. } \\
\text { Objective assessments: After sample collection, glucose } \\
\text { measurements were immediately obtained using a RapidPoint } 405 \\
\text { (Siemens Medical Solutions, Norwood), on all heparinised blood and } \\
\text { effusion samples (not supernatant). }\end{array}$ \\
\hline $\begin{array}{l}\text { Main findings: } \\
\text { (relevant to PICO question): }\end{array}$ & $\begin{array}{l}\text { - Blood-effusion glucose gradient of }<37 \mathrm{mg} / \mathrm{dL}(<2.06 \\
\mathrm{mmol} / \mathrm{L} \text { ) was } 89.5 \% \text { sensitive for the diagnosis of SP but had } \\
\text { a low specificity of } 66.7 \% \text {. }\end{array}$ \\
\hline
\end{tabular}




\begin{tabular}{|c|c|}
\hline & $\begin{array}{l}\text { Blood-effusion gradient of glucose in SP dogs had a mean of } \\
3.3 \mathrm{mmol} / \mathrm{L} \text { and in NSA dogs a mean of } 0.3 \mathrm{mmol} / \mathrm{L} \text { which } \\
\text { was a statistically significant difference. } \\
\text { Blood-effusion gradient of glucose had an area under the } \\
\text { receiver operating characteristics (AUROC) value of } 0.809 \\
\text { which was significant ( } P=0.0013 \text { ) when compared to the } \\
\text { line of identity AUROC value of } 0.5 \text {. } \\
\text { No single biomarker is completely discriminating for SP and } \\
\text { no cut-off offers } 100 \% \text { sensitivity and specificity. }\end{array}$ \\
\hline Limitations: & $\begin{array}{l}\text { - Animals were sampled only once however the biomarker } \\
\text { concentrations can vary as the disease progresses. This can } \\
\text { affect the validity of the results. } \\
\text { - The small sample size reduces the reliability of the results. } \\
\text { - The personnel carrying out cytological evaluation of } \\
\text { peritoneal fluid varied in their levels of training and } \\
\text { experience which could lead to either false negative or false } \\
\text { positives in the diagnosis of SP or NSA which would affect } \\
\text { the reliability of the results. A standardised approach } \\
\text { ensuring people with the same level of training in cytological } \\
\text { evaluation carried out the analysis, would achieve more } \\
\text { reliable results. } \\
\text { The researcher conducting the fluid analysis was not blinded } \\
\text { to patient presentation, clinical signs and other test results, } \\
\text { although the effects of not blinding will have less of an } \\
\text { impact when using objective measurements. } \\
\text { This study was conducted in a referral practice. Patients } \\
\text { presenting are typically at a severe stage in the disease } \\
\text { process. Results from this study may not be directly } \\
\text { applicable to patients with the same disease at an earlier or } \\
\text { milder stage in the disease process, as is often seen in first } \\
\text { opinion general practice. }\end{array}$ \\
\hline
\end{tabular}

\section{Appraisal, application and reflection}

The literature search revealed three papers that were directly relevant to the PICO question outlined. These were three diagnostic test evaluation studies (Bonczynski et al., 2003; Koenig \& Verlander, 2015; and Martiny \& Goggs, 2019).

There were two prospective clinical trials (Szabo et al., 2011; and Guieu et al., 2016) that analysed blood and peritoneal fluid samples following the placement of closed-suction abdominal drains (CSAD) after surgery, rather than evaluating patients in an acute presentation. Although glucose measurements were analysed, both studies did not identify the sensitivity, specificity, positive predictive value (PPV), negative predictive value (NPV) or diagnostic accuracy of any of the tests used and so the studies were not included for summary in this report. However, the outcomes highlighted from these studies were that glucose measurements were not reliable in diagnosing septic peritonitis (SP) in postoperative cases in which the peritoneal fluid sampled was collected from a closed suction drain. The study by Szabo et al. (2011) used an experimental design in which healthy patients underwent abdominal surgery and were then monitored, which reduces the validity of the results to be applied to clinical practice. The results from these studies are specific to these clinical scenarios and the data should not be applied to patients presenting in an acute scenario or with fluid collected by abdominocentesis. 
The diagnostic test evaluation studies (Bonczynski et al., 2003; Koenig \& Verlander, 2015; and Martiny \& Goggs, 2019) all provided a moderate level of evidence. The studies admitted patients to the study group consecutively over a time period and in accordance to pre-defined inclusion criteria which minimises selection bias. In terms of patients selection, Bonczynski et al. (2003) included a wider range of inclusion criteria which meant that all patients with effusions (inflammatory or neoplastic) were admitted to the study group, which may be more representative of cases seen in practice. This study identified a diagnostic sensitivity and specificity of $100 \%$ when using blood to fluid glucose (BFG) differences of $>1.1 \mathrm{mmol} / \mathrm{L}$ to diagnose SP (Bonczynski et al., 2003). However, Martiny \& Goggs (2019) identified that BFG gradients did not have a sensitivity, specificity or diagnostic accuracy of $100 \%$. This was likely due to the patient selection for this study. All patients had to have an effusion as well as systemic inflammatory response syndrome (SIRS) diagnosed at presentation. This meant that the SP group and the control group of nonseptic ascites (NSA) were clinically very similar and were also age-matched. This study identified that blood-effusion gradients were higher in dogs with SP compared to NSA and this was a statistically significant difference. They also identified that blood-effusion gradients had an area under the receiver operating characteristics (AUROC) value of 0.809 which was significant ( $p$-value of 0.0013 ) when compared to the line of identity AUROC value of 0.5 , which means that blood-effusion gradients are able to discriminate between SP and NSA (Martiny \& Goggs, 2019). However, the study did not identify a cut-off value for blood-effusion glucose gradients with reasonable sensitivity or specificity, although they did identify that a cut-off of $<2.06 \mathrm{mmol} / \mathrm{L}$ had a poor specificity of $66.7 \%$ but reasonable sensitivity of $89.5 \%$.

It is important to note that the studies by Bonczynski et al. (2003) and Martiny \& Goggs (2019) both analysed glucose measurements using blood chemistry analysers and blood gas analysers respectively. This can limit the application of the findings in each study to clinical practice as these diagnostic tools are not always readily available. The study by Koenig \& Verlander (2015) overcame this by measuring glucose using a veterinary point of care (POC) glucometer, a tool commonly available in veterinary practice. The study identified that whole blood to peritoneal fluid (WB-PF) concentration differences were insensitive for diagnosis of SP as was plasma to peritoneal fluid, if a cut-off value of $>1.1 \mathrm{mmol} / \mathrm{L}$ was used. However, this study did identify that a plasma to peritoneal fluid (P-PF) glucose concentration difference greater than $>2.1 \mathrm{mmol} / \mathrm{L}(>38 \mathrm{mg} / \mathrm{dL}$ ) supported an accurate diagnosis of SP in dogs with peritoneal effusions, with a diagnostic sensitivity of $88.2 \%$, specificity of $100 \%$, PPV of $100 \%$ and NPV of $90.9 \%$ giving a diagnostic accuracy of $94.6 \%$ (Koenig \& Verlander, 2015). It is also important to note that when using a veterinary POC glucometer, plasma rather than whole blood produced significantly relevant differences $(P<0.001)$. However, there was no relevant difference when using peritoneal fluid rather than peritoneal fluid supernatant $(P=0.140)$ (Koenig \& Verlander, 2015).

All of the diagnostic test evaluation studies (Bonczynski et al., 2003; Koenig \& Verlander, 2015; and Martiny \& Goggs, 2019) carried out a variety of diagnostic tests, including the gold standard reference tests of either cytology and culture and sensitivity, on all patients. This meant that every case of SP was confirmed by cytology and bacterial culture, so the accuracy of the index diagnostic test (blood and peritoneal fluid glucose measurements) was less likely to be overestimated. Each study also contained sufficient information for replicability if needed. However, in the studies by Koenig \& Verlander (2015) and Martiny \& Goggs (2019), the researcher carrying out the fluid analysis was not always blinded to the clinical signs, presentation or results of the other diagnostic test. This can lead to an element of conscious bias due to lack of blind independent interpretation, although the significance of this is less important when the diagnostic tests are measuring an objective variable such as glucose concentrations, as in this case. The main limitation for all the studies analysed in this paper is the small sample size which can result in larger confidence intervals, decreasing the power of the study and potentially, its clinical relevance. It is also important to note that all of the studies (Bonczynski et al., 2003; Koenig \& Verlander, 2015; and Martiny \& Goggs, 2019) collected data from patients in referral practice. It can be argued that these patients may be presenting with a more severe disease status than those seen in first opinion practice, therefore not being representative of all patients presenting at varying stages of disease. This can make it difficult to make direct applications from the data from these studies to first opinion general practice. Furthermore, it is important to note that all the studies (Bonczynski et al., 2003; Koenig \& Verlander, 2015; and Martiny \& Goggs, 2019) only sampled the animals once, typically at the initial presentation. Single time point sampling does not allow for identification of any changes in 
biomarker concentration over time therefore, the effect of disease progression on biomarker concentrations cannot be determined, limiting the reliability of these results.

The current gold standard for the diagnosis of SP in the pre-operative patient is either the identification of intracellular bacteria on cytology of peritoneal fluid or a combination of a positive bacterial culture of peritoneal fluid alongside cytology results confirming an inflammatory peritoneal effusion. Cytology for diagnosis of SP has a reported accuracy of between 57\% (Mueller et al., 2001) to 87\% (Lanz et al., 2001) with bacterial culture results yielding an accuracy of between $50 \%$ (Lanz et al., 2001) to 83\% (Mueller at al., 2001). The wide range in diagnostic accuracy shows a clear limitation to the gold standard. Furthermore, cytological evaluation is subjective and dependent on the skill and expertise of the person analysing the sample. Results from bacterial cultures of peritoneal fluid will require around 2-3 days to yield bacterial growth. This is a clear limitation for the critical patient in which decisions must be made in a timely manner to improve patient outcomes. Therefore, an accurate patient side diagnostic test would be useful in aiding the diagnosis of SP.

In summary, three papers were identified in the literature search, providing a moderate level of strength of evidence. The research has highlighted that a P-PF glucose difference of $>2.1 \mathrm{mmol} / \mathrm{L}$ ( $>38 \mathrm{mg} / \mathrm{dL}$ ) can be used to aid in diagnosis of SP, with a sensitivity of $88.2 \%$, specificity of $100 \%$ and diagnostic accuracy of $94.6 \%$, when the peritoneal fluid has been acquired directly from abdominocentesis during the pre-operative period and if measured using a veterinary POC glucometer (Koenig \& Verlander, 2013). However, when using a biochemistry analyser the difference can be lowered to $1.1 \mathrm{mmol} / \mathrm{L}(>20 \mathrm{mg} / \mathrm{dL}$ ) with $100 \%$ specificity and sensitivity (Bonczynski et al., 2003). Throughout the research presented there is a large variety in suggested cut-off values when measuring glucose differences. This is due to different studies using biochemistry analysers rather than veterinary POC glucometers as well as comparing whole blood versus plasma and peritoneal fluid versus peritoneal supernatant. This makes it challenging to easily generalise the results to clinical practice. A further study could be carried out to directly compare the sensitivity, specificity and diagnostic accuracy when using different analysers and sample types which may make the results easier to summarise and apply to general practice.

Based on the strength of the studies analysed, there is only moderate evidence that glucose measurements are useful as a patient side diagnostic test for septic peritonitis therefore this should not be the sole diagnostic test carried out. Instead, glucose measurements should be used to build the clinical picture, alongside the patients clinical presentation, information gathered from imaging modalities and any results from cytology and / or bacterial culture of peritoneal fluid.

\section{Methodology}

\begin{tabular}{|c|c|}
\hline \multicolumn{2}{|l|}{ Search strategy } \\
\hline $\begin{array}{r}\text { Databases searched and dates } \\
\text { covered: }\end{array}$ & $\begin{array}{l}\text { CAB Abstracts on OVID Platform (2000-2021) } \\
\text { PubMed NCBI (2000-2021) }\end{array}$ \\
\hline Search terms: & $\begin{array}{l}\text { CAB Abstracts: } \\
\text { (dogs or dog or canine or canines) AND (septic) AND (peritonitis or } \\
\text { effusion) AND (glucose) } \\
\text { PubMed: } \\
\text { (dogs or dog or canine or canines) AND (septic) AND (peritonitis or } \\
\text { effusion) AND (glucose) }\end{array}$ \\
\hline Dates searches performed: & 17 Oct 2021 \\
\hline
\end{tabular}




\begin{tabular}{|c|c|}
\hline \multicolumn{2}{|l|}{ Exclusion / Inclusion criteria } \\
\hline Exclusion: & $\begin{array}{l}\text { - Papers not written in English. } \\
\text { - Papers not measuring blood and peritoneal fluid glucose or } \\
\text { not diagnosing septic peritonitis via the gold standard of } \\
\text { culture and sensitivity. This includes any papers not } \\
\text { identified as a diagnostic test evaluation study in which } \\
\text { diagnostic sensitivity and specificity was not identified (not } \\
\text { relevant to PICO question). } \\
\text { - Review articles or conference proceedings. } \\
\text { - Papers with no author name, abstract or DOI number. }\end{array}$ \\
\hline Inclusion: & $\begin{array}{l}\text { Papers that measured glucose in blood and peritoneal fluid as well } \\
\text { as confirmed the diagnosis of septic peritonitis via cytology and / or } \\
\text { bacterial culture. The paper must determine diagnostic sensitivity } \\
\text { and specificity for using glucose measurements to diagnose septic } \\
\text { peritonitis. }\end{array}$ \\
\hline
\end{tabular}

\begin{tabular}{|c|c|c|c|c|c|c|}
\hline \multicolumn{7}{|c|}{ Search outcome } \\
\hline Database & $\begin{array}{c}\text { Number } \\
\text { of } \\
\text { results }\end{array}$ & $\begin{array}{l}\text { Excluded - } \\
\qquad \text { Not } \\
\text { written in } \\
\text { English }\end{array}$ & $\begin{array}{l}\text { Excluded - Not } \\
\text { relevant to } \\
\text { PICO question }\end{array}$ & $\begin{array}{l}\text { Excluded - } \\
\text { Review articles } \\
\text { or conference } \\
\text { proceedings }\end{array}$ & $\begin{array}{l}\text { Excluded - No } \\
\text { author name, } \\
\text { abstract or DOI }\end{array}$ & $\begin{array}{c}\text { Total } \\
\text { relevant } \\
\text { papers }\end{array}$ \\
\hline $\begin{array}{l}\text { CAB } \\
\text { Abstracts }\end{array}$ & 17 & 4 & 9 & 1 & 0 & 3 \\
\hline PubMed & 10 & 0 & 7 & 0 & 0 & 3 \\
\hline \multicolumn{6}{|c|}{ Total relevant papers when duplicates removed } & 3 \\
\hline
\end{tabular}

\section{CONFLICT OF INTEREST}

The authors declare no conflict of interest.

\section{REFERENCES}

1. Bonczynski, J. J., Ludwig, L. L., Barton, L. J., Loar, A. \& Peterson, M. E. (2003). Comparison of Peritoneal Fluid and Peripheral Blood pH, Bicarbonate, Glucose, and Lactate Concentration as a Diagnostic Tool for Septic Peritonitis in Dogs and Cats. Veterinary Surgery. 32(2), 161-166. DOI: https://doi.org/10.1053/jvet.2003.50005

2. Guieu, L-V. S., Bersenas, A. M., Brisson, B. A., Holowaychuk, M. K., Ammersbach, M. A., Beaufrère, H., Fujita, H. \& Weese, J. S. (2016). Evaluation of peripheral blood and abdominal fluid variables as predictors of intestinal surgical site failure in dogs with septic peritonitis following celiotomy and the placement of closed-suction abdominal drains. Journal of the American Veterinary Medical Association. 249(5), 515-525. DOI: https://doi.org/10.2460/javma.249.5.515 
3. Koenig, A. \& Verlander, L. L. (2015). Usefulness of whole blood, plasma, peritoneal fluid, and peritoneal fluid supernatant glucose concentrations obtained by a veterinary point-of-care glucometer to identify septic peritonitis in dogs with peritoneal effusion. Journal of the American Veterinary Medical Association. 247(9), 1027-1032. DOI: https://doi.org/10.2460/javma.247.9.1027

4. Lanz, O. I., Ellison, G. W., Bellah, J. R., Weichman, G. \& VanGilder, J. (2001). Surgical treatment of septic peritonitis without abdominal drainage in 28 dogs. Journal of the American Animal Hospital Association. 37(1), 87-92. DOI: https://doi.org/10.5326/15473317-37-1-87

5. Martiny, P. \& Goggs, R. (2019). Biomarker Guided Diagnosis of Septic Peritonitis in Dogs. Frontiers in Veterinary Science. 6, 208. DOI: https://doi.org/10.3389/fvets.2019.00208

6. Mueller, M. G., Ludwig, L. L. \& Barton, L. J. (2001). Use of closed-suction drains to treat generalized peritonitis in dogs and cats: 40 cases (1997-1999). Journal of the American Veterinary Medical Association. 219 (6), 789-794. DOI: https://doi.org/10.2460/iavma.2001.219.789

7. Szabo, S. D., Jermyn, K., Neel, J. \& Mathews, K. G. (2011). Evaluation of Postceliotomy Peritoneal Drain Fluid Volume, Cytology, and Blood-to-Peritoneal Fluid Lactate and Glucose Differences in Normal Dogs. Veterinary Surgery. 40(4), 444-449. DOI: https://doi.org/10.1111/i.1532-950X.2011.00799.x 


\section{EVIIDEFeE

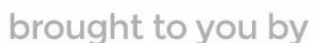 \\ RCVS KNOWLEDGE}

\section{Intellectual Property Rights}

Authors of Knowledge Summaries submitted to RCVS Knowledge for publication will retain copyright in their work, and will be required to grant RCVS Knowledge a non-exclusive license of the rights of copyright in the materials including but not limited to the right to publish, re-

publish, transmit, sell, distribute and otherwise use the materials in all languages and all media throughout the world, and to license or permit others to do so.

\section{Disclaimer}

Knowledge Summaries are a peer-reviewed article type which aims to answer a clinical question based on the best available current evidence. It does not override the responsibility

of the practitioner. Informed decisions should be made by considering such factors as individual clinical expertise and judgement along with patient's circumstances and owners' values. Knowledge Summaries are a resource to help inform and any opinions expressed within the Knowledge Summaries are the author's own and do not necessarily reflect the view of the RCVS Knowledge. Authors are responsible for the accuracy of the content. While the

Editor and Publisher believe that all content herein are in accord with current recommendations and practice at the time of publication, they accept no legal responsibility

for any errors or omissions, and make no warranty, express or implied, with respect to material contained within.

For further information please refer to our Terms of Use.

RCVS Knowledge is the independent charity associated with the Royal College of Veterinary Surgeons (RCVS). Our ambition is to become a global intermediary for evidence based veterinary knowledge by providing access to information

that is of immediate value to practicing veterinary professionals and directly contributes to evidence based clinical decision-making.

https://www.veterinaryevidence.org/

RCVS Knowledge is a registered Charity No. 230886.

Registered as a Company limited by guarantee in England and Wales No. 598443.

Registered Office: Belgravia House, 62-64 Horseferry Road, London SW1P 2AF

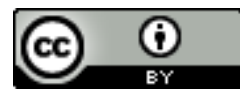

This work is licensed under a Creative Commons Attribution 4.0 International License 